\title{
Reestruturação capitalista e trabalho: notas críticas acerca da economia solidária
}

\author{
Daniela Neves de Sousa \\ Universidade Federal do Rio de Janeiro (UFRJ)
}

\section{Reestruturação capitalista e trabalho: notas críticas acerca da economia solidária}

Resumo: O presente trabalho apresenta uma análise crítica da 'economia solidária' tanto nos seus fundamentos teóricos como na sua implementação prática. $\mathrm{O}$ artigo apresenta dois claros focos de análise: um primeiro que explicita os fundamentos históricos e teóricos da economia solidária e que são localizados no socialismo moderno. Este entendimento, porém, não leva a afirmar, como muitos teóricos o fazem, que a economia solidária é o caminho contemporâneo ao socialismo. Em segundo lugar, e na continuidade, busca-se apresentar que a construção e a propagação dessa falsa consciência não encontram seus alicerces em mudanças de fundo no modo de produção capitalista, ao contrário, verifica-se uma re-atualização. Para tanto, as análises apresentadas tem como interlocutor privilegiado o militante e teórico Paul Singer, que atualmente é quem dá o tom do debate sobre o tema no Brasil.

Palavras-chave: economia solidária, socialismo utópico, reestruturação capitalista.

\section{Restructuring Capital and Labor: Critical Notes about Solidarity Economics}

Abstract: This study presents a critical analysis of 'solidarity economics', regarding both its theoretical foundations as well as its practical implementation. The article has two focuses: the first explains the historic and theoretical foundations of solidarity economics located in modern socialism. This understanding, however, does not lead to the affirmation, as many have made, that solidarity economics is the contemporary road to socialism. Second, the paper maintains that the construction and propagation of this false consciousness is not based on deep changes in the capitalist mode of production. To the contrary, the renovation of this system is recognized. The analyses consider the work in this field of activist and scholar Paul Singer, who currently sets the tone of the debate concerning this issue in Brazil.

Key words: solidarity economics, utopian socialism, capitalist restructuring. 


\section{Introdução}

A reestruturação produtiva, decorrência da dinâmica contemporânea do capital, é portadora de mudanças na economia cujas consequiências são fundamentais para toda a organização da sociedade. Dessa forma, as transformações no mundo do trabalho devem ser submetidas a uma análise atenta, muito menos por suas novidades, mas, essencialmente, por sua funcionalidade em relação ao capital. Assim, compreendemos que as mudanças impostas ao trabalho são resultantes do estágio atual de desenvolvimento das forças produtivas e dos constrangimentos das relações sociais de produção. Portanto, nossa hipótese é de que as atividades de trabalho que vêm sendo organizadas a partir de empreendimentos da chamada 'economia solidária', estando esta em franca expansão, relacionam-se intimamente com formas atuais de desenvolvimento econômico e industrial, caracterizando-se como estratégias de controle sobre o trabalho. Nestes termos, algumas propostas de auto-organização dos trabalhadores, na busca de satisfazer livremente as suas necessidades e combater o desemprego, tornam-se estratégias para satisfazer as necessidades atualizadas do capital.

O estudo das cooperativas de trabalho, e de sua crescente participação estratégica para o desenvolvimento da economia no Brasil, possibilita-nos interpelar como a chamada economia solidária e suas formas concretas de existência, a exemplo, as cooperativas, vêm contribuindo para a mobilização econômica. Isto vem ocorrendo tanto na abertura de postos de trabalho, para absorver parte da superpopulação relativa fora do mercado formal, quanto pela sua proposta mistificadora de alternativa econômico-social para a classe trabalhadora, e também em relação a empresas sublocadas no processo de produção fabril. Desse modo, uma forma de organização do trabalho, baseado na economia solidária, vem ganhando espaço no meio social, na busca de alternativas para superar a crise do desemprego.

O debate sobre a economia solidária ressurge amplamente mobilizado por diversos segmentos da sociedade, com uma variedade de objetivos e interesses. As cooperativas, de um modo geral, sejam elas de produção, de consumo, de crédito, ressurgem no cenário como algumas das formas de organização do trabalho e de alternativa ao desemprego, sob a marca da economia solidária, sendo esta uma suposta contraposição à economia capitalista.

Nestes termos, a noção teórica de economia solidária começou a aparecer no Brasil na década de 1980, mas é prioritariamente na segunda metade da década de 1990 que elas tomam impulso e se multiplicam. Essa 'onda solidária' é resultado do investimento de vários movimentos sociais, organizações não governamentais, categorias e entidades sindicais que buscam novas formas de superação da crise do capital e do trabalho, do desemprego, e forjam estratégias de ação política e organização do trabalho.

Este movimento é claramente perceptível no governo Lula que institucionalizou a partir do seu primeiro ano de mandato uma política centrada na economia solidária, para a qual criou uma secretaria nacional. Em junho de 2003, o Congresso Nacional aprovou projeto de lei do presidente Lula, criando no Ministério do Trabalho e Emprego (MTE) a Secretaria Nacional de Economia Solidária (Senaes) ${ }^{1}$. A direção da Senaes ficou a cargo de um respeitado acadêmico brasileiro, com grande atividade, pesquisa e produção sobre o tema, o economista Paul Singer. A partir de então, a economia solidária alçou o status de política pública de governo.

Mesmo antes da criação da SENAES, as iniciativas de economia solidária no Brasil vinham sendo impulsionadas a partir das ações de vários grupos sociais (movimentos sociais, ONGs, Igrejas, incubadoras...), que apoiavam, entre outras, a constituição e a articulação de cooperativas populares, as redes de produção e comercialização e as feiras de cooperativismo e economia solidária. Ao longo do tempo, esses grupos passaram a articular fóruns estaduais e regionais, mas foi no marco das organizações de entidades, durante as edições do Fórum Social Mundial, que se constituíram as bases de criação do Fórum Brasileiro de Economia Solidária (FBES).

Os números também são expressivos. Os dados do Atlas da Economia Solidária no Brasil, do Ministério do Trabalho e Emprego (BRASIL, 2007), apontam, no segundo semestre de 2005, a identificação de 14.954 empreendimentos solidários em 2.274 municípios brasileiros, sendo 44\% só no Nordeste e 56\% distribuídos nas demais regiões do país.

O objetivo do presente texto é fazer uma problematização radical sobre a teoria e a prática da chamada economia solidária, pois acreditamos que no atual marco sociopolítico, particularmente no que se refere à experiência brasileira, é necessário tornar claros os 'fios invisíveis' que refuncionalizam as saídas propostas pela esquerda contemporânea, e que se apresentam como uma novidade.

\section{O debate sobre a economia solidária: dos socialistas utópicos a Paul Singer}

A economia solidária, ou economia social, não é algo desprezível, considerando o quadro político, as mudanças no mundo do trabalho e as estratégias do capital na sociedade brasileira contemporânea. Ela vem ganhando atenções e polarizando o debate acerca das estratégias de combate ao desemprego, de incentivo à geração de emprego e renda e, sobretu- 
do, de incentivo às ações políticas de combate à chamada 'vulnerabilidade social'.

A economia solidária compreende uma diversidade de práticas econômicas e sociais, organizadas sob a forma de cooperativas, associações, empresas autogestionárias, redes de cooperação, complexos cooperativos, entre outras, que realizam atividades de produção de bens, prestação de serviços, finanças, trocas, comércio e consumo.

A amplitude de temas, experiências e ações que cerca esse amálgama denominado de economia solidária, possibilita, na mesma medida, uma diversidade de debates, análises e proposições sobre o tema. Existe hoje um número muito amplo e muito diferenciado - se considerarmos as vinculações teóricas e políticas - de autores ${ }^{2}$, de estudiosos, de profissionais, de grupos, organizações e de partidos, que vêm produzindo intelectualmente e/ou desenvolvendo atividades nessa linha, Devemos, ainda, destacar a inserção do Estado brasileiro neste quadro, como formulador de políticas e indutor de ações de interesse deste segmento.

Esse setor vem se desenvolvendo no Brasil desde os últimos anos do século passado, constituindo, supostamente, uma resposta da sociedade civil às mudanças nas relações de trabalho, ao desemprego, e à ampliação da pobreza. Já na década de 1990 se observou o surgimento e a multiplicação de organizações e entidades de apoio, assessoramento, agregação e fomento a todo tipo de empreendimento associativo e cooperativo. Em meados de 1991, foram promovidas assessorias sindicais e populares de suporte aos trabalhadores para poderem assumir algumas empresas falidas ou entrar em 'parceria' no capital de investimentos de outras empresas com debilidades de mercado. Três anos depois, várias instituições autogestionárias criaram a Associação Nacional de Trabalhadores de Empresas de Autogestão e Participação Acionária, a Anteag.

Outro agente de grande participação no desenvolvimento ídeo-político da noção de economia solidária, com a criação de cooperativas e associações de trabalhadores, foi o Movimento dos Trabalhadores Rurais Sem Terra (MST), que, através da luta dos moradores do campo, ocuparam territórios e assentaram diversas famílias. Para desenvolver economicamente a produção agrícola familiar e comercial, foram organizadas diversas cooperativas, e capacitados vários técnicos em cooperativismo.

$\mathrm{O}$ meio acadêmico também se mobilizou em torno da discussão da economia solidária e criou, em 1990, a Rede Universitária de Incubadoras Tecnológicas de Cooperativas Populares - Rede Universitária de ITCPs, com o objetivo de assessorar camadas pobres da população na formação, capacitação e inserção de cooperativas de diversos ramos no mercado de trabalho. Estas ITCPs estavam articuladas entre si e inte- gradas à Unitrabalho - fundação voltada à assessoria e aos estudos do movimento operário no Brasil -, hoje Rede Interuniversitária de Estudos e Pesquisas sobre o Mundo do Trabalho. Diversas são, também, as entidades responsáveis pela difusão da economia solidária, com destaque para a Cáritas, órgão do Conferência Nacional dos Bispos do Brasil (CNBB), para a Federação das Cooperativas de Trabalho (Fetrabalho), e para a Fundação de Órgãos para a Assistência Social e Educação (FASE), no Rio de Janeiro.

Os sindicatos, até a década de 1990, adotavam uma postura de resistência a este tipo de atividade, por entender que ficariam enfraquecidos. Mas esta resistência foi progressivamente quebrada e a maioria deles já apóiam abertamente esses empreendimentos de economia social. Hoje, vários sindicatos se empenham na formação e na articulação de grupos, visando à criação de cooperativas habitacionais, de trabalho ou de serviços. Dentre as entidades do movimento sindical, destaque-se a Unisol, do Sindicato dos Metalúrgicos do ABC, e a Agência de Desenvolvimento Solidário (ADS), da Central Única dos Trabalhadores (CUT).

Atualmente, a economia solidária faz parte da agenda do Estado para a implantação de políticas governamentais (municipais, estaduais e nacional), que visem seu desenvolvimento. O Governo Federal criou, no âmbito do MTE, a Secretaria Nacional de Economia Solidária (Senaes), com o objetivo de favorecer o desenvolvimento e a divulgação da economia solidária. O Programa Economia Solidária em Desenvolvimento (parte do Plano Plurianual 20042007 do Governo Federal) prevê a realização de um mapeamento da economia solidária no Brasil, considerando os empreendimentos econômicos solidários e as entidades de apoio, assessoria e fomento. Com base nesse mapeamento será constituído o Sistema Nacional de Informações em Economia Solidária (SIES), composto por uma base nacional e por bases locais de informações que proporcionem visibilidade às iniciativas e ofereçam subsídios aos processos de formulação de políticas públicas.

Esse contexto, mesmo rapidamente reconstituído, permite-nos inferir algumas problemáticas, principalmente de natureza política. Um dos principais desafios para aqueles que analisam a economia solidária no Brasil é chegar à sua definição conceitual e aos dos atributos que a caracterizam, pois essa classificação tem sido dada a tudo que relaciona uma atividade de fins econômicos a supostos princípios ou benefícios na esfera social.

Diante dessa imprecisão de forma e de conceito sobre o tema, a análise e o diálogo crítico com a maior referência teórica no debate sobre economia solidária, Paul Singer, é fundamental.

Para Singer (SINGER; SOUZA, 2000), a economia solidária deve ser entendida como um modo de pro- 
dução e distribuição que é reatualizado temporalmente, a partir da necessidade de inserção dos trabalhadores na economia e na busca de postos de trabalho, em contraposição ao modo de produção capitalista.

A economia solidária, de acordo com o autor, resgata a unidade do processo de produção, onde os trabalhadores seriam proprietários dos meios de produção dos quais se utilizam para a realização do trabalho e desenvolveriam a socialização destes meios a partir do trabalho em associação, o que resultaria de uma síntese entre o modo de produção simples de mercadorias e o capitalismo em seu estágio atual.

Nestes termos, para iluminar a compreensão que está posta na atualidade sobre a economia solidária, Singer sintetiza afirmando a importância dessa proposta e sua alternativa de superação do capitalismo:

A 'economia solidária' surge como modo de produção e distribuição alternativo ao capitalismo, criado e recriado periodicamente pelos que se encontram (ou temem ficar) marginalizados do mercado de trabalho. A 'economia solidária' casa o princípio da unidade entre posse e uso dos meios de produção e distribuição (da produção simples de mercadorias) com o princípio da socialização destes meios (do capitalismo). [...]. O modo solidário de produção e distribuição parece à primeira vista um híbrido entre o capitalismo e a pequena produção de mercadorias. 'Mas, na verdade, ele constitui uma síntese que supera ambos' (SINGER; SOUZA, 2000, p. 13, destaques do autor).

Na compreensão do autor (SINGER; SOUZA, 2000, p. 13), a superação do capitalismo é possível porque na economia solidária os princípios são distintos e opostos aos da economia capitalista: "posse coletiva dos meios de produção pelas pessoas que as utilizam para produzir; gestão democrática da empresa; repartição da receita líquida entre os cooperadores." Por essa estrutura organizacional e ideológica, as experiências autogestionárias da economia solidária são, segundo Singer (SINGER; SOUZA, 2000, SINGER, 2001, 2002), modos concretos de organização do trabalho não capitalista, sendo herdeiras da tradição socialista.

Dessa forma, Singer, e diversos outros autores, apontam que as bases ideológicas da economia solidária estão na histórica crítica ao capitalismo, feita pela classe operária e pelo movimento socialista, como Owen (1771-1858), Fourier (1772-1837), Buchez (1796-1865), Proudhon (1809-1865). Há, para o autor, uma indiscutível afinidade entre as classes trabalhadoras e os princípios que regem a economia solidária. Nos termos de Singer, "Nem todos os trabalhadores rejeitam o capitalismo, mas a maioria deles o faz e por isso, quando se associa para produzir, comprar ou vender ou consumir, o faz sob formas solidárias" (SINGER; SOUZA, 2000, p. 15). Sumariando a formulação de Singer, a construção da economia solidária tem sido, em muitos países e ao longo de muitas gerações, umas das principais formas de luta contra o capitalismo, ao lado da ação de sindicatos e partidos por direitos políticos e sociais.

Se considerarmos a economia solidária como o conjunto de atividades econômicas - de produção, distribuição, consumo, poupança e crédito -, organizadas sob a forma de autogestão, de acordo com Singer, e segundo o SIES e a SENAES (BRASIL, 2007), seus principais atributos são os arrolados a seguir.

a) Cooperação: a existência de interesses e objetivos comuns, a união dos esforços e das capacidades, a propriedade coletiva de bens, a partilha dos resultados e a responsabilidade solidária sobre os possíveis ônus. Envolve diversos tipos de organização coletiva: empresas autogestionárias ou recuperadas (assumida por trabalhadores); associações comunitárias de produção; redes de produção, comercialização e consumo; grupos informais produtivos de segmentos específicos (mulheres, jovens); clubes de trocas.... Na maioria dos casos, essas organizações coletivas agregam um conjunto grande de atividades individuais e familiares.

b) Autogestão: os participantes das organizações exercitam as práticas participativas de autogestão dos processos de trabalho, das definições estratégicas e cotidianas dos empreendimentos, da direção e coordenação das ações nos seus diversos graus e interesses. Os apoios externos, de assistência técnica e gerencial, de capacitação e assessoria, não devem substituir nem impedir o protagonismo dos verdadeiros sujeitos da ação.

c) Dimensão econômica: é uma das bases de motivação da agregação de esforços e recursos pessoais e de outras organizações para produção, beneficiamento, crédito, comercialização e consumo. Envolve o conjunto de elementos de viabilidade econômica, permeados por critérios de eficácia e efetividade, ao lado dos aspectos culturais, ambientais e sociais.

d) Solidariedade: o caráter de solidariedade nos empreendimentos é expresso em diferentes dimensões. Insere-se na justa distribuição dos resultados alcançados; nas oportunidades que levam ao desenvolvimento de capacidades e da melhoria das condições de vida dos participantes; nas relações que se estabelecem com o meio ambiente, expressando o compromisso com um meio ambiente saudável; nas relações que se estabelecem com a comunidade local; na participação ativa nos processos de desenvolvimento sustentável de base territorial, re- 
gional e nacional; nas relações com os outros movimentos sociais e populares de caráter emancipatório; na preocupação com o bemestar dos trabalhadores e consumidores; e no respeito aos direitos dos trabalhadores.

e) Participação: é outra base de motivação da conjugação de sujeitos para o trabalho, desenvolvendo um processo educacional de formação e organização de uma nova cultura política. Envolve um conjunto de elementos de natureza pedagógica, relacionados aos interesses e objetivos dos grupos envolvidos.

No nosso entendimento, todo o conjunto de proposições da economia solidária está encharcado de problemas centrais de natureza política. Por isso, passamos a analisar alguns pontos problemáticos dessas formulações - e, também, porque nossa concepção teórica colide com seus pressupostos.

A concepção dominante sobre a economia solidária, que é marcada pela produção teórica de Singer (em diversos títulos), expressa um claro conteúdo eclético - influenciado nitidamente por idéias socialistas utópicas, socialistas marxistas, anarquistas, social-democratas e reformistas em geral - e polimorfo a diversidade que compõe o conjunto das atividades da economia solidária é exponencialmente imensurável. Essas questões, se fossem de ordem exclusivamente intelectiva, não seriam um problema. Entretanto, como tal concepção é elaborada para fundamentar supostas práticas sociais não-capitalistas, e por vezes, pretensas alternativas de luta anticapitalista, carece de uma formulação saturada de realidade social.

Para nós, nesse trato dedicado à economia solidária - centrado no trabalho e no trabalhador - está contido um modo superficial de analisar os processos históricos e contemporâneos de transformação da sociedade capitalista, em particular a reestruturação da esfera produtiva e as relações sociais de produção. São, assim, isolados determinantes históricos e políticos fundamentais, que envolvem a participação de outros sujeitos centrais na esfera de organização da sociedade: o Estado e o capital, fragmentando a realidade social, que só pode ser pretensamente conhecida na medida em que nos defrontamos com ela como uma totalidade. Isto é facilmente perceptível quando identificamos, na formulação de diversos autores, em especial Singer, a articulação da economia solidária à necessidade contemporânea de combate ao desemprego.

Para resolver o problema do desemprego é necessário oferecer à massa dos socialmente excluídos uma oportunidade real de se reinserir na economia por sua própria iniciativa. Esta oportunidade pode ser criada a partir de um novo setor econômico, formado por pequenas empresas e trabalhadores por conta própria, composto por ex-desempregados, que tenham 'um mercado protegido da competição externa para os seus produtos' (SINGER, 2001, p. 112, destaque do autor).

Nesta relação, desemprego e economia solidária, é considerada apenas a epiderme do fenômeno da reestruturação produtiva, que é o desemprego. Não identifica outros fatores que estão articulados, como a contra-reforma do Estado e seu postulado neoliberal, e, sobretudo, as necessidades do capital no estágio atual de desenvolvimento capitalista.

Neste sentido, podemos afirmar que o atual padrão de acumulação põe em movimento um renovado processo de organização do trabalho, cuja finalidade essencial é a intensificação das condições de exploração da força de trabalho, principalmente nos contextos de crise, incorporando, na parte central da produção de valor, modalidades que aparentemente seriam formas autônomas e independentes de trabalho. São estas formas, sobretudo, atividades na esfera da economia solidária.

Queremos afirmar, assim, que o conteúdo efetivo das formulações da chamada economia solidária pairam apenas na aparência de fenômenos próprios da reestruturação capitalista e da dinâmica reificada da vida social. O que, por outro lado, também expressa que tais fenômenos estão se processando e têm suas bases na existência real, impondo-nos a busca por um rigor analítico, à luz da crítica radical e ontológica do sistema capitalista, e não somente nas 'construções ideais' que se autonomizam frente à realidade. Nestes termos, enumeramos, brevemente, algumas das debilidades da noção de 'economia solidária'.

a) Sua origem. Apesar de temas como autogestão, auto-organização dos trabalhadores, sociedade de 'produtores livres', justiça social, entre outros, estarem vinculados historicamente às origens do socialismo moderno do século 19 , esse conceito - economia solidária - é cunhado na atualidade, nas duas últimas décadas do século 20, sob a marca da 'solidariedade indiferenciada transclassista', resultante dos processos de 'desresponsabilização do Estado' (contra-reforma do Estado no Brasil), e das transformações do capital e suas estratégias de controle sobre o trabalho.

b) Sua composição. A primeira pergunta seria: quais os grupos, entidades, segmentos, ou mesmo quais as práticas econômicas e sociais que compõem a economia solidária? A marca da sua origem aponta que, no Brasil, sua caracterização é a mais diversa possível: desde os moradores de uma comunidade popular que criam uma cooperativa de serviços de limpeza, até patrões e trabalhadores de uma fábrica à beira da falência, que se associam e diri- 
gem-na de modo autogestionário ${ }^{3}$. Destacamos, assim, que, se tal proposta se vincula ao projeto emancipatório em alternativa ao capitalismo, como amparar em seu conteúdo formas de associação tão diferentes e com expressões tão díspares, pois congrega, em suposto consenso de interesses, parcelas da classe capitalista e trabalhadora. A economia solidária congrega também, no mesmo bojo, organizações formais e informais, de representação de trabalhadores ou patronal, associações de interesses sociais, econômicos e políticos, indivíduos comuns, e experiências ligadas ao poder estatal.

c) Seu conteúdo. O conceito de economia solidária, como vem sendo difundido e trabalhado pelos teóricos em geral, e pelos diversos segmentos da sociedade civil, obscurece, ainda mais, a contradição fundamental das relações sociais no capitalismo. As classes sociais fundamentais, a partir do referencial solidário, desreferenciam o conteúdo central da exploração, qual seja: produção coletiva e apropriação privada da riqueza. Assim, o enfoque central da economia solidária destina-se a discutir a 'gestão do trabalho', a 'regulação econômica', ignorando mediações fundamentais do 'modo de produção capitalista', e particularmente do seu estágio atual de desenvolvimento.

\section{Considerações finais}

O desenvolvimento de nossas análises leva-nos a algumas considerações. Como vimos demonstrando, o debate em torno da economia solidária contém vários equívocos que precisam ser debatidos e tematizados criticamente. Vale destacar, principalmente, o fato de que as elaborações da sociedade contemporânea - que considera o desemprego e as mudanças do trabalho apenas como consequiências da crise capitalista; que não apreende as relações das experiências de economia solidária com a produção capitalista - metamorfoseam e 'camuflam' as relações de trabalho em relações mercantis.

Dessa forma, acreditamos que o debate sobre as mudanças na sociedade contemporânea deve rastrear as determinações fundamentais, que relacionam as experiências da economia solidária (as cooperativas de trabalho e de produção). Isto seria feito em consideração ao contexto mais amplo da reestruturação capitalista e, mais precisamente, às relações de produção operadas no contexto da flexibilização - movimento próprio do atual desenvolvimento capitalista.

No nosso entendimento muitos são os conceitos da economia e da política, como autonomia, emprego, trabalho, serviço, que sofrem um processo de al- teração na forma, sem resultar, com isso, mudanças reais em seu conteúdo. Ou são estes conceitos objeto de reinterpretação realizada por intelectuais que se vinculam, direta ou indiretamente, às classes dominantes. Esse processo, que Gramsci (1999) conceituou como 'transformismo', exerce uma função de legitimar as relações de produção capitalista, transformando as necessidades do capital em necessidades do trabalho.

Dessa forma, produzir uma ideologia sobre a ampliação da autonomia dos trabalhadores não cria as condições reais para que esta aconteça. É impossível pensar que na sociedade capitalista atual possam existir formas de trabalho independentes dos ditames do capital, sejam elas subsumidas de modo formal ou real ao capital. Discussões que sustentam esse nível de mistificação pretendem, necessariamente, manter inalterada a dominação e a exploração do trabalho, e desmobilizar, como consequiência, a organização da classe trabalhadora.

As transformações do trabalho no capitalismo contemporâneo põem em movimento um renovado processo de organização, cuja finalidade essencial é a intensificação das condições de exploração da força de trabalho, principalmente nos contextos de crise, incorporando, na parte central da produção de valor, modalidades de trabalho que aparentemente seriam formas autônomas e independentes. Poucas são as análises que situam este processo como formas renovadas de trabalho articuladas à produção capitalista. Também raros são os estudos que entendem a ampliação dessas modalidades de trabalho como uma expansão progressiva das relações capitalistas, vinculando e articulando trabalhos parciais a serviço do capital. Muitas atividades, sob o signo da economia solidária, fazem parte do processo de deslocamento da força de trabalho, antes localizada internamente nas indústrias centrais, para unidades produtivas subcontratadas pelas empresas, vendidas como 'trabalho materializado'. Sobre o assunto, Teixeira (1996, p. 69) comenta:

\section{As grandes unidades de produção contam com um enorme contingente de trabalhadores domésticos, artesanais, familiares, que funcionam como peças centrais dentro dessa cadeia de subcontratação. Constituem-se todos em fornecedores de trabalho 'materializado', porque, agora, a compra e venda da força de trabalho são veladas sob o véu da com- pra e venda de mercadorias semi-elaboradas.}

Tendo como foco a participação das cooperativas de trabalho nas 'teias invisíveis' das relações capitalistas, também afirmamos que a existência das cooperativas nas condições analisadas depende da grande empresa que contrata seu trabalho, sendo estas, muitas vezes, parte do trabalho coletivo do pro- 
cesso de produção da indústria. Assim, muitas cooperativas fazem parte do núcleo produtivo das empresas e, de um modo geral, da totalidade das relações de produção do padrão atual de acumulação. Logo, fica explícito que a descentralização produtiva não elimina a cooperação do trabalho que, por sua vez, é determinada pela atual divisão social e técnica do trabalho.

As debilidades presentes, tanto teóricas como práticas no campo da chamada economia solidária, apresentam um componente inegavelmente mistificador das relações que mediam o capital, enquanto força social em busca de se expandir, e o trabalho, enquanto componente medular do processo de valorização. Ressaltamos também que o conceito de economia solidária se reveste, na atualidade, muito mais de um 'constructo ideal' que não esclarece as relações de produção e de organização do trabalho, apesar de estas estarem referenciadas no movimento da realidade.

Transversal ao debate sobre o trabalho, há um outro núcleo-força que faz a economia solidária muito atraente, principalmente para diversos setores progressistas e de esquerda (sem prejuízo da compatibilidade desse núcleo-força com o ideário liberal e neoliberal). No seio das várias elaborações teóricas sobre o tema, como também nas de Singer, existe um conjunto de conceitos que são considerados atributos importantíssimos da economia solidária e que já foram anunciados por nós anteriormente. Esses conceitos - autogestão, cooperação, dimensão econômica, participação e solidariedade - foram, em sua maioria, extraídos das idéias do movimento socialista do século 19, e incorporados, mais tarde, na passagem do século 19 e início do 20, pela social-democracia européia, na medida em que foram ressignificados e reformados a partir das determinações políticas e teóricas da época.

$\mathrm{O}$ fato desse universo conceitual estar presente na proposta da economia solidária nos possibilita afirmar que há uma grande aproximação entre esta e a social-democracia, no que tange às estratégias de enfrentamento do capitalismo. Ou seja, a idéia de reforma também está presente na economia solidária, só que travestida de conteúdo anti-capitalista. Pois é necessário, na perspectiva da economia solidária, forjar, ainda dentro da ordem capitalista, ações educativas para a construção de um 'novo homem' e uma produção de mercadorias não-capitalista, modo produtivo alternativo. Entretanto, o que observa é que mesmo as experiências mais exitosas, do ponto de vista cultural, tendem a subsumir-se às relações sociais de produção capitalistas.

Os trabalhadores das cooperativas não são formalmente assalariados, mas são pagos a partir da determinação central de mensuração dos salários o valor da força de trabalho - que nestas modalidades são verificadas no quantum de trabalho cristalizado nas mercadorias. Assim, não se elimina a mediação de compra e venda da força de trabalho, apenas altera-se sua forma.

Desse modo, entendemos que a desconcentração produtiva vincula as cooperativas à grande teia interligada do processo de produção. A jornada de trabalho realizada na cooperativa combina-se à jornada dos trabalhadores do complexo central, recriando um 'novo trabalhador coletivo', uma forma de organização que revela a utilização renovada de modalidades de trabalho existentes desde o início do capitalismo. Estas aparentes 'novas' formas de trabalho, que se inserem no movimento de valorização do capital, apontam a presença cada vez mais 'invisível' de um trabalhador coletivo nas teias do processo de produção. A fragmentação atual dos processos de produção remete a um reorganizado processo combinado que põe em movimento uma força coletiva de trabalho através da cooperação.

Ao finalizarmos este trabalho queremos demarcar que a fragmentação, decorrente da reestruturação produtiva, não é despropositada e indefinida. Ao resultado desse fracionamento das relações de trabalho e de produção, segue-se uma constante ameaça nas condições de vida dos trabalhadores. Tais incertezas, como o trabalho precário, o desemprego e a pobreza, implicam um agravamento no poder de organização da classe trabalhadora, que vem demonstrando uma fragilidade, não só em pensar alternativas de confronto ao capital, mas antes disso, em entender os condicionantes reais das mudanças na esfera do trabalho e do capital. Isto, sem dúvida, aumenta o poder das grandes empresas sobre os trabalhadores, e a exploração do capital sobre a potência social do trabalho.

Os sistemas de garantias ao trabalho, criados em alguns países centrais, e as ações reguladoras nos países periféricos, foram fruto do movimento contraditório de 'conquistas' do trabalho e 'interesses' do capital. Mas, sem dúvidas, só foram possíveis devido à existência, naquele momento histórico, de uma ampla força de pressão acumulada pelos trabalhadores na luta de classes, sobretudo, pela existência da ameaça do comunismo. O enfraquecimen- 
to da organização e da força da classe trabalhadora na atualidade, entre outros motivos, está resultando em um processual desmantelamento desses sistemas de proteção, expondo os trabalhadores a condições de trabalho cada vez mais aviltantes. A fragilização conjuntural em que se encontra a classe trabalhadora é travestida pelos propagandistas da burguesia e vendida como o fim do operariado clássico fabril, e, sobretudo, como o advento da era plena do capital, pois este seria agora absoluto.

Não vislumbramos perspectivas imediatas de superação sócio-histórica do sistema capitalista. Na verdade, cabe ao movimento social, e à classe trabalhadora em particular, apresentar tais saídas. Podemos até identificar alguns pólos de resistência de lutas sociais, mas a potencialidade destas é muito limitada no momento presente, uma vez que observamos muito mais o avanço insaciável do processo de valorização. Entretanto, como o homem constrói a história, a reversão de tendências atualmente dominantes, e as possibilidades de superação da ordem do capital, estão sempre latentes no processo histórico.

\section{Referências}

ARROYO, J. T.; SCHUCH, F. (Org.). Solidariedade e sucesso: a experiência do Banco do Povo de Belém. Editado pela Prefeitura de Belém, Pará, 2006.

BRASIL. MTE-Ministério do trabalho e Emprego. Atlas da Economia Solidária no Brasil. Disponível em: <http:/ /www.trabalho.gov.br/ecosolidaria/sies atlas.asp $>$. Acesso em: jul.2007.

GAIGER, L. I. G. Economia solidária no Brasil. Porto Alegre: Ed. da UFRGS, 2004.

FRANÇAFILHO, G.; LAVILLE, J.-L. Economia solidária: uma abordagem internacional. Rio Grande do Sul: Editora da UFRGS, 2004.

GRAMSCI, A. Cadernos do cárcere. Tradução de Carlos Nelson Coutinho com a colaboração de Luiz Sergio Henriques e Marco Aurélio Nogueira. Rio de Janeiro: Editora Civilização Brasileira, v. 1, 1999.

RECH, D. Cooperativas: uma alternativa de organização popular. Rio de Janeiro: Fase e DP\&A, 2000.

SANTOS, B. de S. (Org.). Os processos da globalização. In: _. A globalização e as ciências sociais. São Paulo: Cortez, 2002. p. 25-102.

SINGER, P. Uma utopia militante: repensando o socialismo. Petrópolis: Vozes, 1998.
Globalização e desemprego: diagnóstico e alternativas. São Paulo: Contexto, 2001. (Coleção Zero à Esquerda).

Introdução à 'economia solidária'. São Paulo: Fundação Perseu Abramo, 2002.

SINGER, P.; SOUZA, A. R. (Org.). A 'economia solidária' no Brasil. São Paulo: Contexto, 2000.

TEIXEIRA, F. J. S. Modernidade e crise: reestruturação capitalista ou fim do capitalismo? In: ; OLIVEIRA, M. A. (Org.) Neoliberalismo e reestruturação produtiva: as novas determinações do mundo do trabalho. São Paulo/ Fortaleza: Cortez/UECE, 1966.

\section{Notas}

1 Lein. 10.683, de28 de maio de 2003 e Decreto n. 4.764, de 24 de junho de 2003 .

2 A produção no campo da economia solidária é muito ampla, mas podemos sinalizar algumas das mais importantes no âmbito acadêmico: Arroyo e Schuch (2006), Gaiger (2004), Rech (2000), Singer e Sousa (2000) e Singer (1998, 2001 e 2002), este último, como já é sabido, também tem grande influência na formulação de políticas públicas para o setor.A repercussão deste debate é tal que já propiciou uma análise comparativaentreFrança/Brasil(FRANÇAFILHO; LAVILLE, 2004). Há também que destacar os trabalhos de abrangência internacional patrocinados pelo influente sociológico português Boaventura de Sousa Santos (2002).

3 Neste exemplo, em vez de autogestão poderia ser a co-gestão, mas esta não é a expressão da realidade brasileira.

\section{Daniela Neves de Sousa}

Doutoranda em Serviço Social na Escola de Serviço Social na Universidade Federal do Rio de Janeiro (UFRJ)

Orientador: José Paulo Netto

\section{UFRJ}

Escola de Serviço Social

Avenida Pasteur, 250 - Fundos

Prédio da ESS

Urca

Rio de Janeiro - Rio de Janeiro

CEP: 22290-902 